\title{
A influência das redes sociais sobre as más decisões e aos maus hábitos relacionados à saúde bucal de adolescentes e adultos: Revisão integrativa de literatura
}

\author{
The influence of social networks on poor decisions and bad habits related to the oral health of \\ adolescents and adults: An integrative literature review \\ Influencia de las redes sociales en las malas decisiones y los malos hábitos relacionados con la salud \\ bucodental de adolescentes y adultos: Revisión bibliográfica integradora
}

Recebido: 20/07/2021 | Revisado: 29/07/2021 | Aceito: 30/07/2021 | Publicado: 05/08/2021

\author{
Dayviddy Lucas Magalhães Silva \\ ORCID: https://orcid.org/0000-0002-6708-2659 \\ Centro Universitário de Patos de Minas, Brasil \\ E-mail: dayviddylms@unipam.edu.br \\ Laura Cesário Oliveira \\ ORCID: https://orcid.org/0000-0002-7689-5061 \\ Centro Universitário de Patos de Minas, Brasil \\ E-mail: lauracesario@unipam.edu.br \\ Millena Luiza Vaz da Silveira \\ ORCID: https://orcid.org/0000-0002-9203-8705 \\ Centro Universitário de Patos de Minas, Brasil \\ E-mail: millenalvs@unipam.edu.br \\ Julianne Caixeta Nunes \\ ORCID: https://orcid.org/0000-0001-7560-6005 \\ Centro Universitário de Patos de Minas, Brasil \\ E-mail: juliannecaixeta@unipam.edu.br \\ Thiago de Amorim Carvalho \\ ORCID: https://orcid.org/0000-0003-1153-0931 \\ Centro Universitário de Patos de Minas, Brasil \\ E-mail: thiagocarvalho@unipam.edu.br \\ Fabrício Campos Machado \\ ORCID: https://orcid.org/0000-0003-4603-8795 \\ Centro Universitário de Patos de Minas, Brasil \\ E-mail: fabriciocampos@unipam.edu.br
}

\begin{abstract}
Resumo
Com o aumento da produção de conteúdo digital sobre Odontologia houve também o aumento da divulgação de hábitos e o uso de acessórios nocivos à manutenção de uma saúde bucal satisfatória e sua influência principalmente sobre os adolescentes e os adultos jovens. O objetivo deste trabalho é identificar qual o impacto na saúde bucal de adolescentes e adultos que fazem o uso de alguns dos acessórios e hábitos nocivos tais como o carvão ativado, o piercing oral e aparelhos fakes que são propagados pelas mídias sociais. Trata-se de uma revisão integrativa da literatura realizada sob os parâmetros da estratégia PRISMA para revisões sistemáticas, com busca nas bases de dados PUBMED, Scielo e Biblioteca Virtual em Saúde (BVS). Após a aplicação dos critérios de inclusão e exclusão, 13 artigos foram selecionados para a análise qualitativa. Diversas consequências podem ser ocasionadas pelo uso do carvão ativado, do piercing oral e dos aparelhos falsos, dentre as quais se destacam, a cárie dental, a doença periodontal, lesões não cariosas, lesões em mucosa além de infecções bacterianas e fúngicas. Percebe-se que embora haja muitas vantagens no uso das redes sociais muitas influências podem ser negativas, principalmente no que se diz respeito à saúde, ainda mais quando os conteúdos não são divulgados exclusivamente por pessoas com preparo científico para tal fim. Mais estudos precisam ser realizados, buscando níveis de evidência cada vez mais confiáveis, para entender quais os malefícios e qual a gravidade exata que o uso desses hábitos e acessórios podem causar na saúde bucal.
\end{abstract}

Palavras-chave: Mídias sociais; Saúde bucal; Hábitos.

\section{Abstract}

With the increase in the production of digital content on dentistry there has also been an increase in the dissemination of habits and the use of harmful accessories to maintain satisfactory oral health and its influence mainly on adolescents and young adults. The aim of this paper is to identify what is the impact on the oral health of adolescents 
and adults who make use of some of the accessories and harmful habits such as activated charcoal, oral piercing and fake appliances that are propagated by social media. This is an integrative literature review carried out under the parameters of the PRISMA strategy for systematic reviews, searching the databases PUBMED, Scielo and Biblioteca Virtual em Saúde (BVS). After applying the inclusion and exclusion criteria, 13 articles were selected for qualitative analysis. Several consequences can be caused by the use of activated carbon, oral piercing and false appliances, among which are dental caries, periodontal disease, non-carious lesions, mucosal lesions and bacterial and fungal infections. It can be seen that although there are many advantages in the use of social networks, many influences can be negative, especially with regard to health, especially when the content is not disclosed exclusively by people with scientific preparation for this purpose. More studies need to be conducted, seeking increasingly reliable levels of evidence, to understand the exact harm and severity that the use of these habits and accessories can cause on oral health.

Keywords: Social media; Oral health; Habits.

\section{Resumen}

Con el aumento de la producción de contenidos digitales sobre odontología también ha aumentado la difusión de hábitos y el uso de accesorios nocivos para mantener una salud bucodental satisfactoria y su influencia principalmente en los adolescentes y adultos jóvenes. El objetivo de este trabajo es identificar cuál es el impacto en la salud bucodental de los adolescentes y adultos que hacen uso de algunos de los accesorios y hábitos nocivos como el carbón activado, el piercing oral y los aparatos falsos que se propagan por los medios sociales. Se trata de una revisión bibliográfica integradora realizada bajo los parámetros de la estrategia PRISMA para revisiones sistemáticas, con búsqueda en las bases de datos PUBMED, Scielo y Biblioteca Virtual em Saúde (BVS). Tras aplicar los criterios de inclusión y exclusión, se seleccionaron 13 artículos para el análisis cualitativo. Son varias las consecuencias que puede provocar el uso del carbón activado, el piercing oral y los aparatos postizos, entre las que destacan la caries dental, la enfermedad periodontal, las lesiones no cariosas, las lesiones de la mucosa y las infecciones bacterianas y fúngicas. Se puede ver que aunque hay muchas ventajas en el uso de las redes sociales, muchas influencias pueden ser negativas, sobre todo en lo que se refiere a la salud, especialmente cuando el contenido no es divulgado exclusivamente por personas con preparación científica para ello. Es necesario realizar más estudios, buscando niveles de evidencia cada vez más fiables, para entender cuál es el daño y la gravedad exacta que el uso de estos hábitos y accesorios puede causar en la salud bucodental.

Palabras clave: Medios de comunicación sociales; Salud bucal; Hábitos.

\section{Introdução}

A Odontologia tem baseado a produção de conteúdo nas redes sociais para usuários com e sem formação na área, assim, muita informação veiculada na rede acaba sendo recebida por pessoas que não apresentam conhecimento técnicocientífico suficiente para o julgamento da veracidade das mesmas (Sampaio et al., 2019) o que subsidia a disseminação de notícias falsas, as famigeradas fake news, que foram consideradas pragas cientificas em um editorial publicado pela European Journal of Oral Implantology, sendo um problema para a ciência odontológica (Dias da Silva \& Damien Walmsley, 2019). Muitos influenciadores digitais acabam fazendo propagandas de produtos de uso odontológico que prometem milagres e revoluções difundindo os modismos que acabam trazendo malefícios para a saúde bucal de quem os usa (Pereira et al., 2013). O público-alvo dessas propagandas são os adolescentes e adultos jovens que acabam, por diversos motivos, inclusive a necessidade aceitação social, sendo influenciados (Alves et al., 2014).

Sabe-se que a adolescência é um período da vida compreendido entre a infância e a vida adulta marcado por diversas mudanças, se caracterizando por um momento crítico onde o indivíduo se vê na necessidade de construir uma forma individual de dar-lhe condições de conviver numa sociedade e se inserir em um grupo (Quiroga \& Vitalle, 2013). Sendo assim, a busca por ser aceito em uma sociedade que lhes impõe estereótipos baseados, sobretudo na melhor estética, seja ela corporal e/ou facial faz com que esses adolescentes sejam cada vez mais influenciados e busquem referências em outras pessoas. Assim sendo, o adolescente passa a seguir modismos impostos por pessoas influentes. E é a consolidação desses hábitos e comportamentos de risco que irão interferir na saúde bucal (Pereira et al., 2013). 
Nota-se que a busca pela estética e perfeição vem sendo cada vez mais desejada em nosso contexto atual e para isso as pessoas lançam mão de inúmeros recursos (Fenato et al., 2010). Padrões estéticos impostos pela sociedade e pelas mídias digitais, influenciam diretamente nas opiniões dos indivíduos sobre o que é belo (Alves et al., 2014) assim há uma procura para se atingir a esse padrão. Dentre os recursos utilizados encontram-se, os acessórios em saúde bucal, como os piercings orais (Schimdt et al.,2019), os aparelhos falsos (aparelhos fakes) ou caseiros (Hakami et al., 2020) e o uso do carvão ativado (Silva et al., 2021) os quais podem gerar alterações e modificações orais que geram um conflito entre beleza/modismo e a saúde bucal de quem os usa.

Os aparelhos fakes também conhecidos como aparelhos da moda, aparelhos piratas e aparelhos personalizados são vendidos e instalados sem nenhuma fiscalização por pessoas inabilitadas para o exercício da odontologia, o que gera diversas alterações bucais como, por exemplo, alterações periodontais acompanhadas de mobilidade dental (Pereira et al., 2016). Já o piercing oral muito utilizado como adorno é uma forma de expressão corporal, identidade pessoal, inclusão social a um determinado grupo, porém o uso desse constante desse acessório, sem os devidos cuidados de higienização da própria peça e a manutenção de cuidados de higiene bucal, pode gerar complicações transitórias ou irreversíveis a estrutura dental o que pode comprometer a saúde geral e bucal de quem faz o uso desses aparatos (Schimdt et al.,2019; Martins et al., 2013). O carvão ativado, por sua vez, é amplamente utilizado como clareador dental e pode ser encontrado nos dentifrícios e em pasta/pó a base de carvão, cujo uso é difundido nas mídias sociais através de influenciadores leigos, porém a utilização desse produto pode gerar danos irreversíveis a estrutura dental como o desgaste excessivo do esmalte. (Silva et al., 2021) promovendo mudança de cor e causando um branqueamento, com consequente hipersensibilidade da estrutura dental e alterações periodontais (Palandi et al., 2020).

O objetivo desse estudo é identificar qual o impacto na saúde bucal de adolescentes e adultos que fazem o uso de alguns dos acessórios e hábitos nocivos tais como o carvão ativado, o piercing oral e aparelhos fakes que são propagados pelas diversas mídias sociais.

\section{Metodologia}

O presente estudo trata-se de uma revisão integrativa da literatura atual em que a pergunta do estudo foi elaborada utilizando como base a estratégia PICO (Santos et al., 2007) em que atribui-se P (população) adolescentes e adultos, I (indicador) uso de adereços orais e de substâncias que causam dano a estrutura dental que são influenciadas pelas mídias sociais, C (controle) saúde bucal dos adolescentes e adultos que possuem uma rotina de cuidados em saúde bucal sem adornos e O (desfecho) consequências que o uso dos aparelhos fake, dos piercings orais e o carvão ativado trazem para a saúde bucal.

A pergunta norteadora do estudo foi: quais os impactos dos hábitos nocivos e uso de adornos orais influenciados pelas mídias sociais na saúde bucal de adolescentes e adultos?

A pesquisa foi realizada seguindo o Guia PRISMA (Principais Itens para Relatar Revisões sistemáticas e Metaanálises) (Galvão et al., 2015). Os artigos foram buscados nas bases de dados Pubmed/Medline, Scielo e Biblioteca Virtual em Saúde - BVS. Foram utilizadas as palavras chaves de busca "fake braces" e "oral health" e "teenagers"; "activated charcoal" e "oral health" e "teenagers" acrescido do operador boleano "and" e não foram encontrados artigos elegíveis para a construção da pesquisa. Foi realizada uma nova pesquisa ultilizando as palavras-chave "fashion braces" e "dentistry"; "fake braces" e "oral health"; "oral health" e "oral piercing"; "activated coal" e "dentistry" com o uso do operador boleano "and". Como critério de inclusão foram os artigos encontrados compreendidos nos anos de 2017 a 2021 que estavam disponíveis na íntegra e na língua inglesa. Como critério de exclusão foram os artigos com apenas resumos disponíveis, artigos em outros idiomas que 
não o inglês e artigos que não foram publicados nos últimos cinco anos, além disso, foram excluídos trabalhos inseridos na literatura cinzenta, que compreendem os capítulos de livro, as teses, dissertações, monografias e trabalhos de conclusão de curso, cujo conteúdo não possui revisão pelos pares.

\section{Resultados}

A busca de dados resultou na identificação de 117 artigos potencialmente elegíveis dos quais 93 encontrados na base de dados Pubmed/Medline, 2 na Scielo e 22 na BVS. Não foram utilizadas outras fontes de publicações. O fluxograma para seleção dos artigos está demonstrado na Figura 1.

Figura 1 - Fluxograma do processo de seleção dos estudos primários adaptado do Preferred Reporting Items for MetaAnalyses (PRISMA).

Identificação

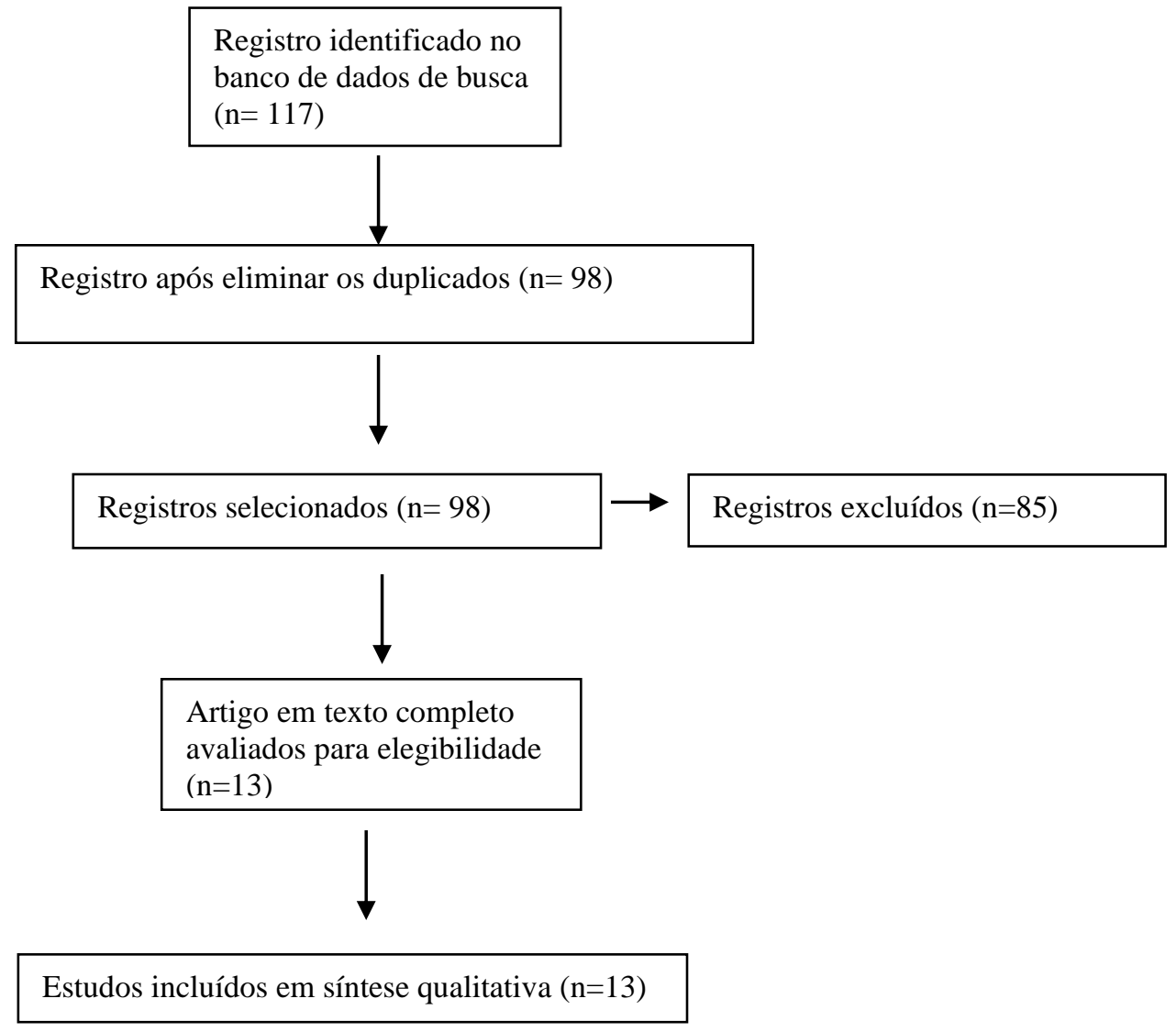

Fonte: Autores.

Foram eliminados 19 artigos que estavam duplicados. A leitura dos títulos e dos resumos dos artigos, com vistas à contemplação dos desfechos e da resposta à pergunta do estudo, foram os métodos utilizados para inclusão e exclusão, tendo sido eliminados 85 publicações. Ao final da análise alcançou-se a amostra final de 13 estudos primários. 
Os estudos selecionados foram caracterizados levando em consideração o autor e ano de publicação do artigo, o periódico de publicação, objetivo e hábitos e acessórios nocivos à saúde bucal, bem como o impacto desses sobre a saúde bucal. Tal caracterização está apresentada no Quadro 1.

Quadro 1 - Caracterização do estudo segundo autor/ano, periódico, objetivo, modismo e impacto na saúde bucal.

\begin{tabular}{|c|c|c|c|c|}
\hline Autor/Ano & Periódico & Objetivo & $\begin{array}{l}\text { Acessórios/Hábitos } \\
\text { nocivos }\end{array}$ & Impacto na saúde Bucal \\
\hline $\begin{array}{l}\text { Alhazmi et al., } \\
2021 .\end{array}$ & BMC oral health & $\begin{array}{l}\text { Identificar } \\
\text { comportamentos } \\
\text { relacionados à saúde bucal } \\
\text { pela utilização de corpos } \\
\text { estranhos. }\end{array}$ & Aparelhos falsos. & $\begin{array}{l}\text { Lesões bucais, câncer, ulcerações, } \\
\text { cárie, deslocamento dentário. }\end{array}$ \\
\hline $\begin{array}{l}\text { Hakami et al., } \\
2020 .\end{array}$ & BMC oral health & $\begin{array}{lcr}\text { Investigar } & \text { os } & \text { efeitos } \\
\text { relacionados ao uso de } \\
\text { aparelhos ortopédicos na } \\
\text { qualidade de dida } \\
\text { relacionada à saúde bucal. }\end{array}$ & Aparelhos Falsos. & $\begin{array}{l}\text { Dor física, limitação funcional, } \\
\text { mudança na coloração dos dentes, } \\
\text { alteração de paladar, problemas ao } \\
\text { pronunciar palavras. }\end{array}$ \\
\hline $\begin{array}{l}\text { Sorooshian\&Ka } \\
\text { marozaman, } \\
2018 .\end{array}$ & $\begin{array}{l}\text { Revista Paulista de } \\
\text { Medicina }\end{array}$ & $\begin{array}{l}\text { Sustentar base sobre o uso } \\
\text { de aparelhos falsos e os } \\
\text { malefícios trazidos por ele. }\end{array}$ & Aparelhos Falsos. & $\begin{array}{l}\text { Danos aos dentes, gengivas, lábios, } \\
\text { ossos e câncer. }\end{array}$ \\
\hline $\begin{array}{l}\text { Ziebolz et al., } \\
2019\end{array}$ & $\begin{array}{l}\text { Diagnostic } \\
\text { Microbiology and } \\
\text { Infectious Disease }\end{array}$ & $\begin{array}{l}\text { Investigar prevalência de } \\
\text { bactérias patogênicas } \\
\text { periodontais em diferentes } \\
\text { sítios de pacientes que } \\
\text { utilizam piercing na língua }\end{array}$ & Piercing oral & $\begin{array}{l}\text { Cárie dentária, recessão gengival, } \\
\text { progressão da doença periodontal, } \\
\text { trauma de tecidos moles, bolsa } \\
\text { periodontal }\end{array}$ \\
\hline $\begin{array}{l}\text { Schmidt et al., } \\
2019\end{array}$ & $\begin{array}{l}\text { International } \\
\text { Journal of Dental } \\
\text { hygiene }\end{array}$ & $\begin{array}{l}\text { Investigar associação de } \\
\text { piercings orais com saúde } \\
\text { ou alterações periodontais } \\
\text { em uma série de casos }\end{array}$ & Piercing oral & $\begin{array}{l}\text { Bolsas periodontais, recessões } \\
\text { gengivais, defeitos dentais, fraturas } \\
\text { dentárias e lascamentos }\end{array}$ \\
\hline $\begin{array}{l}\text { Ziebolz et al., } \\
2019\end{array}$ & $\begin{array}{ll}\text { Clinical } & \text { oral } \\
\text { investigations } & \end{array}$ & $\begin{array}{l}\text { Avaliar a saúde bucal o } \\
\text { comportamento bucal e a } \\
\text { qualidade de vida de } \\
\text { pacientes que utilizam } \\
\text { piercing de língua }\end{array}$ & Piercing oral & $\begin{array}{l}\text { Inchaço, Sangramento, dor, } \\
\text { infecções fúngicas e bacterianas, } \\
\text { trauma de tecidos moles e duros, } \\
\text { recessão gengival, doença } \\
\text { periodontal, rachaduras no esmalte, } \\
\text { abrasões em forma de calha, } \\
\text { alterações de osso alveolar em } \\
\text { dentes anteriores inferiores, defeitos } \\
\text { dentais não cariosos }\end{array}$ \\
\hline $\begin{array}{l}\text { Covello et al., } \\
2020\end{array}$ & $\begin{array}{l}\text { International journal } \\
\text { of environmental } \\
\text { research and public } \\
\text { health }\end{array}$ & $\begin{array}{l}\text { Verificar o conhecimento } \\
\text { das complicações e dos } \\
\text { riscos e observar quais os } \\
\text { riscos dos piercings orais }\end{array}$ & Piercing oral & $\begin{array}{l}\text { Recessão gengival, fratura dental, } \\
\text { gengivite, periodontite, abrasão } \\
\text { dental, perda de inserção, } \\
\text { problemas na ATM, espessamento } \\
\text { de frênulo lingual, língua bifurcada, } \\
\text { neuralgia trigeminal atípica, lesões } \\
\text { de tecidos moles da língua, } \\
\text { queloide hipertrófica lingual. }\end{array}$ \\
\hline $\begin{array}{l}\text { Junco et al., } \\
2017\end{array}$ & $\begin{array}{l}\text { International dental } \\
\text { journal }\end{array}$ & $\begin{array}{l}\text { Avaliar os efeitos imediatos } \\
\text { e em longo prazo em } \\
\text { estudantes de odontologia } \\
\text { sobre os conhecimentos de } \\
\text { piercing oral após um } \\
\text { programa de treinamento e } \\
\text { avaliar se intervenções } \\
\text { educativas sobre o assunto } \\
\text { surge efeito nos } \\
\text { adolescentes }\end{array}$ & Piercing oral & $\begin{array}{l}\text { Problemas dentários, periodontais, } \\
\text { fraturas de esmalte, mau } \\
\text { posicionamento dental, recessão } \\
\text { gengival, colonização por cândida } \\
\text { albicans }\end{array}$ \\
\hline
\end{tabular}




\begin{tabular}{|c|c|c|c|c|}
\hline $\begin{array}{l}\text { King et al., } \\
2018\end{array}$ & dental & $\begin{array}{l}\text { Estabelecer } \\
\text { conhecimentos, } \\
\text { comportamentos e atitudes } \\
\text { dos cirurgiões dentistas } \\
\text { frente ao aconselhamento } \\
\text { fornecido aos pacientes } \\
\text { sobre o uso do piercing oral }\end{array}$ & Piercing oral & $\begin{array}{l}\text { Complicações agudas: inchaço, dor, } \\
\text { deficiência na fala e na mastigação, } \\
\text { hemorragia, hematoma, cicatrização } \\
\text { retardada, ferida por punção, } \\
\text { laceração, traumatismo dentário, } \\
\text { alergia, disfagia e hipersalivação; } \\
\text { Complicações crônicas: dor, } \\
\text { infecção, inchaço, sangramento, } \\
\text { hiperplasia de tecidos, trauma de } \\
\text { tecidos moles, recessão gengival, } \\
\text { trauma dental, dor dentária, } \\
\text { deficiência de fala, distúrbios de } \\
\text { paladar, ingestão de piercing, } \\
\text { hipersalivação, reação galvânica, } \\
\text { migração dentária, disfagia, } \\
\text { deficiência mastigatória / alimentar, } \\
\text { gengivite, acúmulo de placa }\end{array}$ \\
\hline Vaz et al., 2018 & $\begin{array}{l}\text { Journal of Applied } \\
\text { Oral Science }\end{array}$ & $\begin{array}{l}\text { Avaliar a eficácia do } \\
\text { clareamento dental após o } \\
\text { uso de pastas de dentes } \\
\text { clareadoras com carvão } \\
\text { ativado, covarine azul, } \\
\text { peróxido de hidrogênio ou } \\
\text { microesferas }\end{array}$ & Carvão ativado & Desgaste excessivo do esmalte. \\
\hline $\begin{array}{l}\text { Greenwall et al., } \\
2019\end{array}$ & $\begin{array}{l}\text { British Dental } \\
\text { Journal }\end{array}$ & $\begin{array}{l}\text { Oferecer conhecimentos } \\
\text { atuais sobre pastas de dentes } \\
\text { e pós de carvão ativado com } \\
\text { base em evidências e } \\
\text { alegação dos fabricantes }\end{array}$ & Carvão ativado & $\begin{array}{l}\text { A escovação com pastas à base de } \\
\text { carvão ativado pode gerar mais } \\
\text { malefícios do que benefícios. } \\
\text { Quanto mais potencial abrasivo o } \\
\text { creme dental em conjunto com o pó } \\
\text { de carvão tiver, maior é a remoção } \\
\text { de manchas extrínsecas, porém } \\
\text { maior é a perda de substância da } \\
\text { superfície do dente. } \\
\text { O carvão não ajuda nas causas da } \\
\text { halitose e pode prejudicar os efeitos } \\
\text { dos dentifrícios na halitose. } \\
\text { Causa impactos negativos em } \\
\text { paciente com doença periodontal. } \\
\text { O uso de carvão tem capacidade de } \\
\text { branqueamento e não de } \\
\text { clareamento. }\end{array}$ \\
\hline $\begin{array}{l}\text { Palandi et al., } \\
2020\end{array}$ & $\begin{array}{l}\text { Journal Esthetic } \\
\text { Restorative }\end{array}$ & $\begin{array}{l}\text { Avaliar a mudança de cor e } \\
\text { propriedades do esmalte } \\
\text { corado artificialmente após } \\
\text { a escovação com pó de } \\
\text { carvão ativado combinado } \\
\text { ou não de dentifrícios } \\
\text { convencionais e clareadores } \\
\text { em relação ao peróxido de } \\
\text { carbamida }\end{array}$ & Carvão ativado & $\begin{array}{l}\text { Por conta da abrasividade dos pós } \\
\text { de carvão ativado, eles removem } \\
\text { manchas extrínsecas do esmalte } \\
\text { promovendo mudança de cor e } \\
\text { causando um branqueamento. }\end{array}$ \\
\hline $\begin{array}{l}\text { Franco et al., } \\
2019\end{array}$ & Operative dentistry & $\begin{array}{l}\text { Avaliar se o pó de carvão } \\
\text { ativado exerce algum efeito } \\
\text { clareador nos dentes }\end{array}$ & Carvão ativado & $\begin{array}{l}\text { Os pós à base de carvão vegetal não } \\
\text { são eficazes para clareamento } \\
\text { dental quando comparados com } \\
\text { clareador dental. }\end{array}$ \\
\hline
\end{tabular}

Fonte: Autores.

Após análise dos 13 estudos selecionados com base na metodologia é possível notar que o uso dos hábitos e acessórios nocivos à saúde bucal, abordados neste estudo, podem causar alterações específicas como cárie dental, doença periodontal, alterações regressivas do esmalte dental, alterações ortodônticas, e lesões em mucosa, dentre outras alterações. 


\section{Discussão}

Percebe-se que há uma modificação na presença de alterações bucais em pacientes que apresentam algum hábito ou apetrecho prejudicial à saúde bucal e a ausência de tais alterações nos que não fazem seu uso, tendo como exemplo o estudo feito por Schmidt et al. (2019) acerca dos piercings orais e o estudo de Sorooshian e Kamarozaman (2018) referente aos aparelhos da moda. Temos também que produtos como as pastas a base de carvão ativado podem tirar a atenção de produtos conhecidos, que realmente levam benefícios à saúde bucal como a pasta de dente convencional contendo flúor, fazendo o paciente substituir sua utilização por um produto de evidência científica ainda inconclusiva (Greenwall et al., 2019). De maneira geral os hábitos e acessórios nocivos influenciados pelas mídias sociais e prejudiciais à saúde bucal abordados podem causar cáries (Alhazmi et al., 2021; Sorooshian \& Kamarozaman, 2018; Ziebolz et al., 2019; Covello et al., 2020), progressão da doença periodontal (Junco et al., 2017; Covello et al., 2020; Sorooshian \& Kamarozaman, 2018; Ziebolz et al., 2019; Schmidt et al., 2019) e alterações em tecido gengival (Sorooshian \& Kamarozaman, 2018; Schmidt et al., 2019; Covello et al., 2020; Junco et al., 2017; King et al., 2018). A alteração em comum encontrada entre os três hábitos/acessórios nocivos estudados (Carvão ativado, Aparelhos da Moda e Piercing oral) foi a influência sob a doença periodontal (Junco et al., 2017; Covello et al., 2020; Sorooshian \& Kamarozaman, 2018; Ziebolz et al., 2019; Schmidt et al., 2019; Greenwall et al., 2019).

Sabe-se que o tratamento ortodôntico é realizado para tratar má oclusão e sanar problemas estéticos dos pacientes, no entanto por ser um tratamento de alto custo muitos jovens recorrem a pessoas não especializadas (Hakami et al., 2020). Outro agravante é a utilização de aparelhos falsos (aparelhos fakes) sem indicação de um profissional, já que são considerados símbolos de status, riqueza e estilo pelos adolescentes (Hakami et al., 2020) que juntamente com os adultos jovens são os principais público alvo uma vez que são facilmente influenciáveis pelas mídias sociais e não costumam buscar informações relacionados ao uso dos aparelhos fakes (Alhazmi et al., 2021). Esses adornos são comercializados em ruas, balcões e sites na internet, possuem uma variedade de formas com diversos ornamentos, como diamantes, personagens, elásticos de várias cores, vale lembrar que a utilização desses aparelhos não possui nenhuma finalidade terapêutica servindo apenas como "acessório" (Sorooshian \& Kamarozaman, 2018). Após análise dos 3 artigos encontrados acerca do tema temos que o uso dos aparelhos fake traz malefícios para a saúde bucal como as como ulcerações (Alhazmi et al., 2021), mudança na coloração dos dentes (Hakami et al., 2020), cárie dentária por causarem alteração no esmalte (Alhazmi et al., 2021), problemas ao pronunciar palavras (Hakami et al., 2020), danos aos dentes, gengivas, ossos e lábios (Sorooshian \& Kamarozaman., 2018), deslocamento dentário (Alhazmi et al., 2021), dor física (Hakami et al., 2020), limitação funcional (Hakami et al., 2020) e alterações no paladar (Hakami et al., 2020). A literatura ainda traz a possibilidade do surgimento do câncer oral (Sorooshian \& Kamarozaman., 2018; Alhazmi et al., 2021), devido a presença de algumas substâncias como o chumbo e o cádmio na composição desses aparelhos.

Acerca do uso de piercing oral, percebe-se que a sua utilização implica no surgimento de inúmeras complicações orais (King et al., 2018) representando um risco a saúde bucal (Covello et al., 2020) e causando efeitos imediatos e a longo prazo (Junco et al., 2017), observa-se também que pacientes que usam o adorno demonstram pior condição de saúde dental e periodontal em relação aos que não o utilizam (Ziebolz et al., 2019). As principais alterações bucais encontradas em pacientes que utilizam o acessório segundo a análise dos 6 artigos encontrados sobre o tema foram a recessão gengival (Ziebolz et al., 2019; Junco et al., 2017; Covello et al., 2020; King et al., 2018; Ziebolz et al., 2019; Schmidt et al., 2019) e a presença de alterações periodontais (Ziebolz et al., 2019; Junco et al., 2017; Covello et al., 2020; Ziebolz et al., 2019; Schmidt et al., 2019) sendo estas as principais alterações citadas em comum em ambos os estudos. Foram ainda encontradas diversas outras alterações associadas ao uso do piercing oral, como cárie dentária (Ziebolz et al., 2019), traumas de tecido mole (Ziebolz et al., 
2019) (Ziebolz et al., 2019), bolsas periodontais (Ziebolz et al., 2019; Schmidt et al., 2019), defeitos dentais (Schmidt et al., 2019), fraturas dentais em nível de esmalte, esmalte e dentina e esmalte dentina e polpa(Junco et al., 2017; Covello et al., 2020; Schmidt et al., 2019), traumas de tecido duro (Ziebolz et al., 2019), edema e sangramento periodontal e da mucosa oral, além de dor, infecções fúngicas e bacterionas, além de lesões não cariosas como a abrasão (Ziebolz et al., 2019; Junco et al., 2017; Covello et al., 2020); gengivite (Covello et al., 2020; King et al., 2018), perda de inserção periodontal (Covello et al., 2020); disfunções na articulação temporomandibular e na língua (Covello et al., 2020). Cabe ao cirurgião dentista e aos profissionais da área de odontologia entender as principais complicações relacionadas ao uso do piercing oral e saber como gerenciá-las corretamente, fornecendo aos pacientes que utilizam conselhos adequados (King et al., 2018).

Em relação ao hábito de se utilizar o carvão ativado para a higiene bucal, pode-se observar que a estética na sociedade atual mostra que os dentes brancos são considerados um padrão perfeito de beleza, tornando o clareamento dental um tratamento popular (Franco et al., 2019). Este tratamento quando realizado de forma correta com produtos em concentrações ideais e com profissionais especializados é um procedimento conservador, seguro e eficaz, porém com um custo elevado (Franco et al., 2019). Por outro lado, tem se buscado alternativas com baixo custo e de solução rápida, amplamente divulgadas nas mídias sociais (Franco et al., 2019; Greenwall et al., 2019) e uma delas é o pó de carvão ativado. Este produto tem sido cada vez mais utilizado, e aumenta sua popularidade já que, várias pessoas influentes das redes sociais fazem postagens e propagandas sobre tais formulações (Greenwall et al., 2019), alegando juntamente com os fabricantes, se tratar de um produto com capacidade clareadora, natural, com propriedades antibacterianas e antissépticas (Franco et al., 2019; Greenwall et al., 2019), entretanto, as preparações contém compostos inorgânicos e aromatizantes com a tentativa de ajudar no combate a halitose (Greenwall et al., 2019).

Os pós de carvão atuam removendo manchas extrínsecas e depósitos na superfície do esmalte por conta da sua abrasividade e dessa forma fazem o branqueamento dos dentes (Greenwall et al., 2019; Palandi et al., 2020), além disso, em alguns produtos são adicionados o covarine azul, que deposita uma camada fina azul semitransparente que se opõe ao amarelo, criando efeitos visuais de dentes mais brancos (Vaz et al., 2018; Palandi et al., 2020). O que difere do clareamento em que é utilizado agentes clareadores dentais que são aplicados profissionalmente e possuem a capacidade de atuar de forma intrínseca sobre a dentina e esmalte (Greenwall et al., 2019; Palandi et al., 2020). Por conta de sua alta abrasividade, o uso de carvão ativado provoca diversos malefícios à saúde bucal como: desgaste da superfície do dente (Greenwall et al., 2019; Vaz et al., 2018; Franco et al., 2019), hipersensibilidade em consequência do desgaste dentário (Greenwall et al., 2019), em pacientes com doença periodontal o carvão acumula profundamente nos tecidos provocando uma descoloração cinza nos tecidos periodontais (Greenwall et al., 2019), não é eficaz para o clareamento dental (Franco et al., 2019), gera preocupações sobre a incidência de cárie uma vez que são comercializados carvão não fluoretado (Palandi et al., 2020; Greenwall et al., 2019), e os que contém flúor tem capacidade limitada uma vez que o carvão tem alta capacidade de absorção (Greenwall et al., 2019), por conta de sua natureza absortiva o carvão ativado limita os efeitos dos aromatizantes e não neutraliza as causas da halitose (Greenwall et al., 2019). A literatura não é consistente quanto aos efeitos benéficos do branqueamento em consequência do uso de pós de carvão ativado (Franco et al., 2019; Palandi et al., 2020), nem sobre a segurança deste para o esmalte dentário (Palandi et al., 2020).

\section{Conclusão}

Percebe-se que embora haja muitas vantagens no uso das redes sociais especialmente, nos tempos de distanciamento social em que a pandemia forçou a sociedade a estar, seja para estudos, interação social, muitas influências podem ser 
negativas, principalmente no que se diz respeito à saúde, ainda mais quando os conteúdos não são produzidos e divulgados exclusivamente por pessoas com preparo técnico científico para tal fim. No campo da saúde bucal, a influência (ou má influência) digital pode ocasionar diversos danos no que concerne ao uso de acessórios orais como os aparelhos falsos (aparelhos fakes) e os piercings orais, e o uso de carvão ativado para a higiene bucal diária, através dos quais pode-se observar várias as alterações bucais tais como deslocamento dentário, lesões bucais e dor física quando se fala em aparelhos da moda; recessão gengival, doença periodontal e traumatismo dentário em casos de uso de piercing oral e desgaste excessivo do esmalte e hipersensibilidade nas situações onde se faz uso de carvão ativado. A cárie é uma manifestação comum ao uso dos aparelhos falsos e do piercing oral. Todas os hábitos e acessórios orais estudados apresentam influência no aumento do risco para a doença periodontal. A literatura acerca do tema é escassa e muitas vezes inconclusiva, apesar de se tratar de um assunto de extrema importância, visto que se presencia uma sociedade que busca seguir padrões que são impostos por uma população que tem o poder de influenciar e nem sempre de maneira baseada em evidência científica. Mais estudos precisam ser realizados, buscando níveis de evidência cada vez mais confiáveis, para entender quais os malefícios e qual a gravidade exata que o uso do carvão ativado, aparelhos falsos e piercing oral causam na saúde bucal.

\section{Referências}

Alhazmi, A. S., Al Agili, D. E., Aldossary, M. S., Hakami, S. M., Almalki, B. Y., Alkhaldi, A. S., \& Shubayr, M. A. (2021). Factors associated with the use of fashion braces of the Saudi Arabian Youth: application of the Health Belief Model. BMC oral health, 21(1), 251. https://doi.org/10.1186/s12903-021-01609-w

Alves, G. N., \& Aras, W. M. D. F. (2014). Percepção de pacientes em relação à estética dentaria. Rev. Saúde Com., 10(2), 161-171. https://periodicos2.uesb.br/index.php/rsc/article/view/297/241

Covello, F., Salerno, C., Giovannini, V., Corridore, D., Ottolenghi, L., \& Vozza, I. (2020). Piercing and Oral Health: A Study on the Knowledge of Risks and Complications. International journal of environmental research and public health, 17(2), 613. https://doi.org/10.3390/ijerph17020613

Dias da Silva, M. A., \& Damien Walmsley, A. (2019). Notícias falsas e educação odontológica. British Dental Journal, 226 (6), 397-399. https://doi.org/10.1038/s41415-019-0079-z

Fenato, M. C., Miura, C. S. N., \& Boleta-Ceranto, D. C. F. (2010). Piercing bucal: sua saúde vale esse modismo?. Arq. Ciênc. Saúde UNIPAR, 14(2), 157-161. https://www.revistas.unipar.br/index.php/saude/article/view/3419/2321

Franco, M. C., Uehara, J., Meroni, B. M., Zuttion, G. S., \& Cenci, M. S. (2020). The Effect of a Charcoal-based Powder for Enamel Dental Bleaching. Operative dentistry, 45(6), 618-623. https://doi.org/10.2341/19-122-L

Galvão, T. F., Pansani, T. S. D. A., \& Harrad, D. (2015). Principais itens para relatar Revisões sistemáticas e Meta-análises: A recomendação PRISMA. Epidemiologia e Serviços de Saúde, 24(2), 335-342. https://doi.org/10.5123/S1679-49742015000200017

Greenwall, L. H., Greenwall-Cohen, J., \& Wilson, N. (2019). Charcoal-containing dentifrices. British Dental Journal, 226(9), 697-700. https://doi.org/10.1038/s41415-019-0232-8

Hakami, Z., Chung, H. S., Moafa, S., Nasser, H., Sowadi, H., Saheb, S., Bokhari, A. M., \& Anderson, N. K. (2020). Impactoffashionbraceson oral healthrelatedqualityoflife: a web-basedcross-sectionalstudy. BMC oral health, 20(1), 236. https://doi.org/10.1186/s12903-020-01224-1

Junco, P., Barrios, R., Ruiz, M. J., \& Bravo, M. (2017). Educational intervention about oral piercing knowledge among dental students and adolescents at schools. International dental journal, 67(5), 294-298. https://doi.org/10.1111/idj.12297

King, E. M., Brewer, E., \& Brown, P. (2018). Oral piercings and their complications - how confident are we as a profession?. British dental journal, 224(11), 887-895. https://doi.org/10.1038/sj.bdj.2018.435

Martins, A. H., Mendes, M., Bottan, E. R., Neto, M. U., \& Marín, C. (2013). Piercing (oral e perioral) e complicações à saúde: a percepção de um grupo de portadores do adorno. Odontol. Clín.-Cient, 12(4), 287-291. http://revodonto.bvsalud.org/scielo.php?script=sci_arttext\&pid=S1677-38882013000400010

Quiroga, F. L., \& Vitalle, M. (2013) O adolescente e suas representações sociais: apontamentos sobre a importância do contexto histórico. Physis:Revista de Saúde Coletiva, 23(3), 863-878 . http://dx.doi.org/10.1590/s0103-73312013000300011.

Palandi, S., Kury, M., Picolo, M., Coelho, C., \& Cavalli, V. (2020). Effects of activated charcoal powder combined with toothpastes on enamel color change and surface properties. Journal of Esthetic and Restorative Dentistry 32(8), 783-790. https://doi.org/10.1111/jerd.12646

Pereira, C., Veiga, N., Amaral, O., \& Pereira, J. (2013). Comportamentos de saúde oral em adolescentes portugueses. Revista Portuguesa de Saúde Pública, 31(2), 145-152. http://dx.doi.org/10.1016/j.rpsp.2013.03.002. 
Research, Society and Development, v. 10, n. 10, e84101018503, 2021

(CC BY 4.0) | ISSN 2525-3409 | DOI: http://dx.doi.org/10.33448/rsd-v10i10.18503

Pereira, M. A., Souza, F. M., Queiroz, P. A., Vilela, D. D. C., \& Cardoso, J. A. (2016). Exercício ilegal da Ortodontia e suas consequências clínicas. Revista Bahiana de Odontologia, 7(2), 126-131. 10.17267/2238-2720revbahianaodonto.v7i2.794 .

Santos, C. M. C., Pimenta, C. A. M., \& Nobre, M. R. C., (2007). The PICO strategy for the research question construction and evidence search. Revista Latino-Americana de Enfermagem, 15(3), 508-511. https://doi.org/10.1590/S0104-11692007000300023

Sampaio, C., Ramos, J. P., \& Maciel, I. M. E. (2019). Representação social da odontologia segundo a mídia - aspectos a serem discutidos. Univ. Cid. São Paulo, 31(2), 187-193. https://publicacoes.unicid.edu.br/index.php/revistadaodontologia/article/view/832

Schmidt, J. C., Calderaro, S., Weiger, R., \& Walter, C. (2019). Ontheassociationbetween oral piercings and periodontal conditions-A case series. International Journal of Dental Hygiene, 17(4), 318-326. https://doi.org/10.1111/idh.12403

Silva, E. T., Batista, S. G., Diogo, F. S. N. \& Tuñas, I. T. C. (2021). Influenciadores digitais e a publicidade de pó à base de carvão ativado como agente de clareamento dental: Um alerta para dentistas e seus pacientes. Revista Brasileira de Odontologia., 78(1), e1983. http://dx.doi.org/10.18363/rbo.v78.2021.e1983

Sorooshian, S., \&Kamarozaman, A. A. (2018). Fashion braces: na alarming trend. Sao Paulo Medical Journal, 136(5), 497-498. https://doi.org/10.1590/15163180.2018.0296250718

Vaz, V., Jubilato, D. P., Oliveira, M., Bortolatto, J. F., Floros, M. C., Dantas, A., \& Oliveira Junior, O. B. (2019). Whitening toothpaste containing activated charcoal, blue covarine, hydrogen peroxide or microbeads: which one is the most effective?. Journal of Applied Oral Science,27, e20180051. https://doi.org/10.1590/1678-7757-2018-0051

Ziebolz, D., Söder, F., Hartl, J. F., Kottmann, T., Rinke, S., Merle, C. L., \&Schmalz, G. (2019). Prevalence of periodontal pathogenic bacteria at different oral sites of patients with tongue piercing - results of a cross sectional study. Diagnostic microbiology and infectious disease, 95(4), 114888. https://doi.org/10.1016/j.diagmicrobio.2019.114888

Ziebolz, D., Söder, F., Hartl, J. F., Kottmann, T., Rinke, S., \&Schmalz, G. (2020). Comprehensive assessment of dental behaviour and oral status in patients with tongue piercing-results of a cross-sectional study. Clinical oral investigations, 24(2), 971-977. https://doi.org/10.1007/s00784-019-03002-y 